УДК 514.765.1

\title{
GEODESIC MAPPINGS OF SPACES WITH SPECIAL VECTOR FIELDS
}

\author{
V. Kiosak ${ }^{1}$, O. Lesechko ${ }^{1}$ \\ ${ }^{1}$ Odessa State Academy of Civil Engineering and Architecture
}

\begin{abstract}
The paper investigates a special type of pseudo-Riemannian spaces - spaces that allow special vector fields. The specialization of vector fields is mainly reduced to the ability to determine the metric tensor by the combination of vectors or their derivatives.

With the development of the theory of relativity and the theory of Ricci flows, instead of the metric tensor, a linear combination of the metric tensor and the Ricci tensor began to be used.

In this work the vector fields are studied, the covariant derivative of which is proportional to the Ricci tensor.

One of the main methods of modeling physical and mechanical systems using pseudoRiemannian spaces is modeling along mechanical trajectories. The mechanical trajectories are geodetic lines. Therefore, it is natural to have a scientific interest in non-trivial geodetic mappings.

Conformal mappings and some geometric properties of spaces that allow special vector fields were studied in the works of V. A. Kiosak and I. J. Hinterleitner. Geodetic mappings of such spaces have not been studied before.

The research is carried out using the linear form of the basic equations of the theory of geodetic mappings. The equations, conditions of their integration and their differential extensions are studied in the work.

As a result of the research, the system of basic equations is simplified and reduced to a known and previously studied type of the equations. The type of system, if it is necessary, coincides with the system for Einstein spaces, which allow non-trivial geodetic mappings. This opens wide opportunities for further research, but requires consideration of space specifics that allow special vector fields.

The developed methods can be used to study Ricci solitons and other issues related with Ricci streams. The very concept of Ricci flows allowed us to prove the well-known Poincare hypothesis. It is necessary to note that the integration conditions for the equations that characterize the vector fields, studied in this work, coincide with the equations given by Ricci solitons.

The research is carried out locally, in tensor form, without any restrictions as for the metric tensor and the signature of the studied spaces.
\end{abstract}

Keywords: pseudo-Riemannian spaces; special vector fields; geodesic mapping.

\section{ГЕОДЕЗИЧНІ ВІДОБРАЖЕННЯ ПРОСТОРІВ ЗІ СПЕЦІАЛЬНИМИ ВЕКТОРНИМИ ПОЛЯМИ}

\author{
Кіосак В. А. ${ }^{1}$, Лесечко О. В. ${ }^{1}$ \\ ${ }^{1}$ Одеська державна академія будівництва та архітектури
}

Анотація: В роботі досліджується спеціальний тип псевдоріманових просторів просторів, що допускають спеціальні векторні поля. Спеціалізація векторних полів, в основному, зводиться до можливості визначать метричний тензор через комбінацію векторів або їх похідних.

3 розвитком теорії відносності та теорії потоків Річчі замість метричного тензора почали застосовувати лінійну комбінацію метричного тензора та тензора Річчі.

В представленому дослідженні вивчаються векторні поля, коваріантна похідна від яких, пропорційна тензору Річчі.

Одним із основних методів моделювання фізичних та механічних систем за допомогою псевдоріманових просторів $\epsilon$ моделювання по траєкторіям руху. Траєкторіями руху $\epsilon$ 
геодезичні лінії. I тому, природним $є$ науковий інтерес до нетривіальних геодезичних відображень.

Конформні відображення та деякі геометричні властивості просторів, що допускають спеціальні векторні поля, вивчались в роботах В. А. Кіосака та І. Й. Гінтерляйтнер. Геодезичні відображення таких просторів раніше не вивчались.

Дослідження ведуться за допомогою лінійної форми основних рівнянь теорії геодезичних відображень. В роботі вивчаються самі рівняння, умови їх інтегрування та їх диференціальні подовження.

В результаті досліджень система основних рівнянь спрощена та зведена до відомого та раніше дослідженого виду рівнянь. Вид системи, за необхідністю, співпадає з системою для просторів Ейнштейна, що допускають нетривіальні геодезичні відображення. Це відкриває широкі можливості для подальших досліджень, але вимагає врахування специфіки просторів, що допускають спеціальні векторні поля.

Розроблені методи можуть бути застосовані для вивчення солітонів Річчі та інших питань, пов'язаних з потоками Річчі. Саме поняття потоків Річчі дозволило довести відому гіпотезу Пуанкаре. Зауважимо, що умови інтегрування для рівнянь, які характеризують векторні поля, що вивчаються в цій роботі, співпадають з рівняннями, якими задаються солітони Річчі.

Дослідження ведуться локально, в тензорній формі, без обмежень на знак метричного тензора та сигнатуру просторів, що вивчаються.

Ключові слова: псевдоріманові простори, спеціальні векторні поля, геодезичні відображення. 


\section{INTRODUCTION}

Special vector fields in pseudo-Riemannian spaces $V_{n}$ were studied by many authors. The research usually proceeded by imposing some limitations of differential type. For example, a vector field $v^{i}$, that complies with conditions:

$$
v_{, j}^{i}=\alpha \delta_{j}^{i}+\beta_{j} v^{i}
$$

here $\delta_{j}^{i}$ are Kronecker symbols, and comma, is a sign of covariant derivative with a respect to connectivity of $V_{n}$, is called a developable.

There are some special types of developable fields depending on the choice of $\alpha$ and $\beta_{i}$

1. Concircular vector field: $\beta_{i}$ is a gradient, $\alpha$ is some function.

2. Special concircular vector field: $\beta_{i}=0, \alpha$ is some function.

3. Convergent vector field: $\beta_{i}=0, \alpha=$ const .

4. Parallel vector field: $\beta_{i}$ is some vector, $\alpha=0$.

5. Absolute parallel vector field: $\alpha=0, \beta_{i}=0$.

On the other hand vector field $\Lambda_{i}-$

$$
\Lambda_{i, j}+\Lambda_{j, i}=2 R_{i j}+c g_{i j}
$$

is a called a vector field that defines a Ricci soliton. Here $R_{i j}$ is a Ricci tensor, $g_{i j}$ is a metric tensor for $V_{n}$, and $c$ is some constant.

When the vector $\Lambda_{i}$ is gradient, then the soliton is called a gradient Ricci soliton. There are three types of solitons depending on a sign of the constant $c$ : divergent, convergent and constant. Or in other words, covariant derivative of a vector fielad is a linear combination of internal objects of a given space. Taking into account algebraic restrictions, authors introduce $\varphi($ Ric $)$ - vector fields, namely fields that satisfy the equations:

$$
\varphi_{i, j}=s R_{i j}, s_{, i}=0 .
$$

It is clear that $\varphi$ (Ric) - fields can belong to any of the above-mentioned types depending on the choice of $R_{i j}$ and $s$. Some geometric properties of the described vector fields are studied in works $[2,3]$.

\section{ANALYSIS OF LITERARY DATA AND RESOLVING THE PROBLEM}

The beginnings of the mapping theory can be found in the work of ancient Greek mathematician Apollonius of Perga "Conics", where some inversion are studied in respect to circle, ellipse, parabola, hyperbola. Another important step towards modern theory of mappings is represented by the work of Lagrange on dynamic systems and their modelling.

The construction of classical theory of mappings started in the middle XIXth century in works of Italian geometer E. Beltrami, who treated mappings of surfaces on a plane, namely those mappings which transform a geodesic line into a straight line. The development of tensor analysis and its application to differential geometry resulted in basic fundamental results in works of T. Levi-Civita, H. Weyl, T. Thomas $[8,10,11]$. 
The theory of mappings attracted attention of many mathematicians and physicists which were interested in an application of these results in modelling of dynamic processes.

Furthermore, a motion of some types of mechanic systems, many processes in gravitational and electromagnetic fields, in solid matters follows trajectories that can be treated as geodesic lines of a space with affine connectivity or pseudo-Riemannian space. It is enables by a regime when outer forces are absent or their motion is carried out along certain curves with a curvature vector coinciding with a vector of generalized outer forces.

The particular role among geometric objects is played by geodesic lines and their generalizations. This was a reason for a definition (since E. Beltrami's work) of geodesic mappings as mappings preserving geodesic lines. The famous Beltrami theorem, a cornerstone of modern theory of geodesic mappings was published in 1865. It states that geodesic mappings on flat spaces are permitted only by spaces of constant curvature. Over 120 years ago this result was generalized by A.V. Pogorelov. He treated pseudo-Riemannian spaces with minimal conditions on smoothness of metric.

An important contribution to the general patterns of modern theory of geodesic mappings was made by T. Levi-Civita, T. Thomas, H. Weyl, A. Z. Petrov, A. S. Solodovnikov, G. I. Kruchkovich, M. S. Siniukov [8, 9, 10, 11]. A detailed review can be found in the work of A. V. Aminova and in the chapter of M. S. Siniukov's monograph [1,9].

\section{PURPOSE AND TASKS OF THE STADY}

The aim of the paper is a research on new characteristics of pseudo-Riemannian spaces that permit special vector fields and their mappings.

An object of the study is represented by special pseudo-Riemannian spaces, which contain vectors with covariant derivative which is proportional to Ricci tensor, as far as by their non-trivial geodesic mappings.

A subject of research is represented by differential equations, their integrability conditions and differential extensions, characterizing whether a given pseudo-Riemannian space permits a certain type of mapping. Systems of equations that determine the abovementioned mappings are reduced to re-defined system of algebraic equations. By introduction of additional limitations we are able to solve some problems related to geometric properties of pseudo-Riemannian spaces that permit or do not permit geodesic mappings.

Methods of research are classic methods of Riemannian geometry. A research is conducted locally, in a class of sufficiently smooth functions with an application of tensor methods and without any limitations imposed on sign-definite state or signature of a metric.

\section{BASIC RESULTS}

Integrability conditions (1) can be written down as follows

$$
\varphi_{\alpha} R_{i j k}^{\alpha}=s\left(R_{i j, k}-R_{i k, j}\right) .
$$

Taking into account properties of a Riemann tensor $R_{i j k}^{h}$, we obtain

$$
\varphi_{\alpha} R_{i j k}^{\alpha}=s R_{i j k, \alpha}^{\alpha} .
$$

Wrapping (3), we pass to the following expression

$$
\varphi_{\alpha} R_{k}^{\alpha}=\frac{s}{2} R_{, k},
$$

here $R$ is a scalar curvature. 
A bijective correspondence between points of pseudo-Riemannian spaces $R_{. i, .}^{\alpha \beta}$ with a metric tensor $g_{i j}$ and $\bar{V}_{n}$ with a metric tensor $\bar{g}_{i j}$, when every geodesic line of $V_{n}$ finds a correspondence in a geodesic line of $\bar{V}_{n}$ is called a geodesic mapping.

Geodesic mapping that differs from homothetic is called non-trivial.

An existence of non-trivial solutions for a linear form of basic equations of theory of geodesic mappings is a necessary and sufficient condition for an existence of non-trivial geodesic mappings.

A linear form of basic equations of theory of geodesic mappings takes a shape of the following $[9, \mathrm{p} .121]$ :

$$
\begin{aligned}
& \alpha_{i j, k}=\lambda_{i} g_{j k}+\lambda_{i} g_{i k} ; \\
& n \lambda_{i, j}=\mu g_{i j}+a_{\alpha i} R_{j}^{\alpha}-a_{\alpha \beta} R_{. i j .}^{\alpha \beta},
\end{aligned}
$$

here $\mu=\lambda_{\alpha, \beta} g^{\alpha \beta}, R_{j}^{i}=R_{\alpha j} g^{\alpha i}, R_{i j}^{h{ }^{k}}=R_{i j \alpha}^{h} g^{\alpha k}$.

A linear form of basic equations of theory of geodesic mappings takes a shape of the following [9, p.123]

$$
(n-1) \mu_{, i}=2(n+1) \lambda_{\alpha} R_{i}^{\alpha}+a_{\alpha \beta}\left(2 R_{. i, .}^{\alpha \beta}-R_{, i}^{\alpha \beta}\right) .
$$

Solutions (5) and metric tensors $V_{n}, \bar{V}_{n}$ are connected by an expression

$$
\begin{aligned}
& a_{i j}=e^{2 \psi} \bar{g}^{\alpha \beta} g_{\alpha i} g_{\beta j}, \\
& \lambda_{i}=-e^{2 \psi} \bar{g}^{\alpha \beta} g_{\alpha i} \psi_{\beta},
\end{aligned}
$$

where $\bar{g}^{i j}$ are elements of an inverse matrix to $\bar{g}_{i j}$;

$$
\psi_{i}=\frac{1}{2(n+1)} \partial_{i} \ln \left|\frac{\bar{g}}{g}\right| .
$$

Let us prove the following statement.

Lemma 1. When pseudo-Riemannian space $V_{n}$ permits non-trivial geodesic mappings, then for a tensor $a_{i j}$ and a vector $\lambda_{i}$ the following conditions are true

$$
\lambda_{i \alpha} a_{j}^{\alpha}-\lambda_{j \alpha} a_{i}^{\alpha}=0
$$

here $\lambda_{i j}=\lambda_{i, j}$.

\section{Proof.}

Integrability conditions for equations (5) can be written down as follows

$$
a_{\alpha i} R_{j k l}^{\alpha}+a_{\alpha j} R_{i k l}^{\alpha}=\lambda_{l i} g_{j k}+\lambda_{l j} g_{i k}-\lambda_{k j} g_{i l}-\lambda_{k i} g_{j l} .
$$

Multiplying (11) by $a_{m}^{l}$, wrapping by index $l$ and re-assigning $m$, we arrive at

$$
a_{\alpha i} R_{j k \beta}^{\alpha} a_{l}^{\beta}+a_{\alpha j} R_{i k \beta}^{\alpha} a_{l}^{\beta}=a_{l}^{\alpha} \lambda_{l i} g_{j k}+a_{l}^{\alpha} \lambda_{l j} g_{i k}-\lambda_{k i} a_{j l}-\lambda_{k j} a_{i l} .
$$

Symmetrizing by indices $l$ and $k$, and taking into account the equation (11), canceling the terms we obtain

$$
\left(a_{i}^{\alpha} \lambda_{\alpha k}-a_{k}^{\alpha} \lambda_{\alpha i}\right) g_{j l}+\left(a_{i}^{\alpha} \lambda_{\alpha l}-a_{l}^{\alpha} \lambda_{\alpha l}\right) g_{k j}+\left(a_{j}^{\alpha} \lambda_{\alpha k}-a_{k}^{\alpha} \lambda_{\alpha j}\right) g_{i l}+\left(a_{j}^{\alpha} \lambda_{\alpha l}-a_{l}^{\alpha} \lambda_{\alpha j}\right) g_{i k}=0 .
$$

Wrapping by indices $j$ and $l$, we can see that equations (10) are true. 
Thus, the lemma is proved.

Theorem 1. When pseudo-Riemannian space $V_{n}$, permitting $\varphi($ Ric $)$ vector fields, permits non-trivial geodesic mappings, then vectors $\varphi_{i}$ and $\lambda_{i}$ are colinear, or in other words

$$
\varphi_{i}=\rho \lambda_{i},
$$

here $\rho$ some invariant.

Proof.

Taking a covariant derivative of the latter and paying due attention to (5), we arrive at

$$
\begin{aligned}
& \lambda_{\alpha} R_{j k l}^{\alpha} g_{i m}+\lambda_{i} R_{m j k l}+\lambda_{\alpha} R_{i k l}^{\alpha} g_{j m}+\lambda_{j} R_{m i k l}+a_{\alpha i} R_{j k l, m}^{\alpha}+a_{\alpha j} R_{i k l, m}^{\alpha}= \\
& =\lambda_{l i, m} g_{j k}+\lambda_{l j, m} g_{i k}-\lambda_{k i, m} g_{j l}-\lambda_{k j, m} g_{i l} .
\end{aligned}
$$

Wrapping the latter by $l$ and $m$, we obtain

$$
\lambda_{\alpha} R_{j k i}^{\alpha}+\lambda_{\alpha} R_{i k j}+\lambda_{i} R_{j k}+\lambda_{j} R_{i k}+a_{i}^{\alpha} R_{k j \alpha, \beta}^{\beta}+a_{j}^{\alpha} R_{k i \alpha, \beta}^{\beta}=\lambda_{\alpha i,}^{\alpha} g_{j k}+\lambda_{\alpha j,}^{\alpha} g_{i k}-\lambda_{k i, j}-\lambda_{k j, i} .
$$

Multiplying (11) by $\varphi^{l}$ and wrapping by $l$, we pass to the expression:

$$
a_{\alpha i} R_{j k \beta}^{\alpha} \varphi^{\beta}+a_{\alpha j} R_{i k \beta}^{\alpha} \varphi^{\beta}=\varphi^{\alpha} \lambda_{\alpha i} g_{j k}+\varphi^{\alpha} \lambda_{\alpha j} g_{i k}-\lambda_{k j} g_{i l}-\lambda_{k j} \varphi_{i}-\lambda_{k i} \varphi_{j} .
$$

As far as (3) is true we can transform the above-formulated equations into a shape

$$
\begin{aligned}
& s\left(\lambda_{\alpha} R_{j k i}^{\alpha}+\lambda_{\alpha} R_{i k j}+\lambda_{i} R_{j k}+\lambda_{j} R_{i k}-\lambda_{\alpha i}{ }^{\alpha} g_{j k}-\lambda_{\alpha j,}^{\alpha} g_{i k}+\lambda_{k i, j}+\lambda_{k j, i}\right)= \\
& =\lambda_{k j} \varphi_{i}+\lambda_{k i} \varphi_{j}-\varphi^{\alpha} \lambda_{\alpha i} g_{j k}-\varphi^{\alpha} \lambda_{\alpha j} g_{i k} .
\end{aligned}
$$

Alternating by indices $k, j$ and taking into account properties of a Riemann tensor, we can write down the following

$$
s\left(4 \lambda_{\alpha} R_{i k j}^{\alpha}+\lambda_{j} R_{i k}-\lambda_{k} R_{i j}-\lambda_{\alpha j,}^{\alpha} g_{i k}+\lambda_{\alpha k}^{\alpha} g_{i j}\right)=\varphi_{j} \lambda_{k i}-\varphi_{k} \lambda_{i j}-\varphi^{\alpha} \lambda_{\alpha j} g_{i k}+\varphi^{\alpha} \lambda_{\alpha k} g_{i j} .
$$

Then, multiplying by $\lambda^{i}$ and wrapping by $i$, the latter equations will be transformed into

$$
s\left(\lambda_{j} \lambda_{\alpha} R_{k}^{\alpha}-\lambda_{k} \lambda_{\alpha} R_{j}^{\alpha}-\lambda_{\alpha j,}^{\alpha} \lambda_{k}+\lambda_{\alpha k}^{\alpha} \lambda_{j}\right)=\varphi_{j} \lambda_{\alpha} \lambda_{k}^{\alpha}-\varphi_{k} \lambda_{\alpha} \lambda_{j}^{\alpha}-\varphi^{\alpha} \lambda_{\alpha j} \lambda_{k}+\varphi^{\alpha} \lambda_{\alpha k} \lambda_{j} .
$$

After certain transformations we obtain

$$
\lambda_{j}\left(s \lambda_{\alpha} R_{k}^{\alpha}+s \lambda_{\alpha k,}^{\alpha}-\varphi^{\alpha} \lambda_{\alpha k}\right)-\lambda_{k}\left(s \lambda_{\alpha} R_{j}^{\alpha}+s \lambda_{\alpha j,}^{\alpha}-\varphi^{\alpha} \lambda_{\alpha j}\right)=\varphi_{j} \lambda_{\alpha} \lambda_{k}^{\alpha}-\varphi_{k} \lambda_{\alpha} \lambda_{j}^{\alpha} .
$$

Let us multiply the latter by $\xi^{j}$ and group it, then the following expression appears

$$
s \lambda_{\alpha} R_{k}^{\alpha}+s \lambda_{\alpha k,}^{\alpha}-\varphi^{\alpha} \lambda_{\alpha k}=\stackrel{1}{c} \lambda_{\alpha} \lambda_{k}^{\alpha}+\stackrel{2}{c} \varphi_{k}+\stackrel{3}{c} \lambda_{k}
$$

where $\lambda_{\alpha} \xi^{\alpha}=1 ; \varphi_{\alpha} \xi^{\alpha} \stackrel{\text { def }}{=} c ; \lambda_{\alpha} \lambda_{\beta}^{\alpha} \xi^{\beta} \stackrel{\text { def }}{=}-{ }^{2} c ;\left(s \lambda_{\alpha} R_{\beta}^{\alpha}+s \lambda_{\alpha \beta}{ }^{\alpha}-\varphi^{\alpha} \lambda_{\alpha \beta}\right) \xi^{\alpha} \stackrel{\text { def }}{=} \stackrel{3}{c}$.

The equation (21) can be changed by substitution of (22) into a form

$$
\stackrel{1}{c} \lambda_{j} \lambda_{\alpha} \lambda_{k}^{\alpha}-\stackrel{1}{c} \lambda_{k} \lambda_{\alpha} \lambda_{j}^{\alpha}+\stackrel{2}{c} \lambda_{j} \varphi_{k}-\stackrel{2}{c} \lambda_{k} \varphi_{j}=\varphi_{j} \lambda_{\alpha} \lambda_{k}^{\alpha}-\varphi_{k} \lambda_{\alpha} \lambda_{j}^{\alpha} .
$$

Grouping the latter

$$
\varphi_{j}\left(\lambda_{\alpha} \lambda_{k}^{\alpha}+\stackrel{2}{c} \lambda_{k}\right)-\varphi_{k}\left(\lambda_{\alpha} \lambda_{j}^{\alpha}+\stackrel{2}{c} \lambda_{j}\right)=\stackrel{1}{c} \lambda_{j} \lambda_{\alpha} \lambda_{k}^{\alpha}-{ }_{c}^{1} \lambda_{k} \lambda_{\alpha} \lambda_{j}^{\alpha} .
$$


When wrapped with a vector that corresponds to $\varphi_{\alpha} \eta^{\alpha}=1$, and ${ }^{1} c \lambda_{\alpha} \eta^{\alpha} \neq 1$, it takes a shape

$$
\lambda_{\alpha} \lambda_{k}^{\alpha}+\stackrel{2}{c} \lambda_{k}=\stackrel{1}{\tau} \lambda_{\alpha} \lambda_{k}^{\alpha}+\stackrel{2}{\tau} \lambda_{k}+\stackrel{3}{\tau} \varphi_{k}
$$

where $\stackrel{1}{c} \lambda_{\alpha} \eta^{\alpha}=\stackrel{1}{\tau} ;-\stackrel{1}{c} \lambda_{\alpha} \lambda_{\beta}^{\alpha} \eta^{\beta}=\stackrel{2}{\tau} ;\left(\lambda_{\alpha} \lambda_{\beta}^{\alpha}+\stackrel{2}{c} \lambda_{\beta}\right) \eta^{\beta}=\stackrel{3}{\tau}$.

Substituting (25) in (24), we arrive at

$$
\varphi_{i} \lambda_{j}-\varphi_{j} \lambda_{i}=0
$$

or otherwise $\varphi_{i}=\rho \lambda_{i}$, here $\rho=\left(\begin{array}{l}1 \\ c\end{array}\right)^{-1}$.

Theorem 1 is proved.

Lemma 2. In case of non-trivial geodesic mapping of pseudo- Riemannian spaces that permit $\varphi($ Ric $)$-fields, vector $\lambda_{i} \mathrm{i}$ is an eigenvector of tensor $a_{i j}$, namely

$$
\lambda^{\alpha} a_{\alpha i}=u \lambda_{i}
$$

here $u$ is some invariant.

\section{Proof.}

Let us take a covariant derivative of (14)

$$
\varphi_{i, j}=\rho_{j} \lambda_{i}+\rho \lambda_{i, j}
$$

Symmetrizing the latter, we see that

$$
\rho_{i}=\stackrel{1}{\rho} \lambda_{i}
$$

and then (27) takes a shape of

$$
\varphi_{i, j}=\stackrel{1}{\rho} \lambda_{i} \lambda_{j}+\rho \lambda_{i, j} .
$$

It is known that tensor $a_{i j}$ and a Ricci tensor are limited by a condition

$$
a_{\alpha i} R_{j}^{\alpha}-a_{\alpha j} R_{i}^{\alpha}=0 .
$$

Taking into account the definition of $\varphi($ Ric $)$-fields, we can formulate the following expression

$$
a_{i}^{\alpha} \varphi_{\alpha, j}-a_{j}^{\alpha} \varphi_{\alpha, i}=0 .
$$

Substituting (30), and applying Lemma 1, we obtain

$$
\lambda_{i} a_{j}^{\alpha} \lambda_{\alpha}-\lambda_{j} a_{i}^{\alpha} \lambda_{\alpha}=0
$$

Multiplying by $\xi^{i}$, we can see that formula (27) is true, while $u=\lambda_{\alpha} a_{\beta}^{\alpha} \xi^{\beta}$.

The lemma is proved.

Equation (19) can be re-written as follows due to (14) and (30)

$$
4 s \lambda_{\alpha} R_{i k j}^{\alpha}=\left(s \lambda_{\alpha j,}^{\alpha}-\rho \lambda^{\alpha} \lambda_{\alpha j}\right) g_{i k}-\left(s \lambda_{\alpha k,}^{\alpha}-\rho \lambda^{\alpha} \lambda_{\alpha k}\right) g_{i j} .
$$

The latter equation can be wrapped by $i, k$ 


$$
s \lambda_{\alpha j,}^{\alpha}-\rho \lambda^{\alpha} \lambda_{\alpha j}=\frac{4 s}{n-1} \lambda_{\alpha} R_{j}^{\alpha} .
$$

Let us substitute the latter expression into (34)

$$
\lambda_{\alpha} W_{i j k}^{\alpha}=0 .
$$

Here Weyl tensor implies

$$
W_{i j k}^{h}=R_{i j k}^{h}-\frac{1}{n-1}\left(\delta_{k}^{h} R_{i j}-\delta_{j}^{h} R_{i k}\right) .
$$
follows:

On the other hand, taking into account (14), the equation (17) can be written down as

$$
a_{\alpha i} R_{j k \beta}^{\alpha} \lambda^{\beta}+a_{\alpha j} R_{i k \beta}^{\alpha} \lambda^{\beta}=\lambda^{\alpha} \lambda_{\alpha i} g_{j k}+\lambda^{\alpha} \lambda_{\alpha j} g_{i k}-\lambda_{k j} g_{i l}-\lambda_{k j} \lambda_{i}-\lambda_{k i} \lambda_{j} .
$$

Applying (38) and (34), we arrive at

$$
a_{\alpha i} v^{\alpha} g_{j k}-v_{j} a_{i k}+a_{\alpha j} v^{\alpha} g_{i k}-v_{i} a_{j k}=\lambda^{\alpha} \lambda_{\alpha i} g_{j k}+\lambda^{\alpha} \lambda_{\alpha j} g_{i k}-\lambda_{k j} \lambda_{i}-\lambda_{k i} \lambda_{j} .
$$

The above equation can be wrapped by $j, k$

$$
\left(a_{\alpha i} v^{\alpha}-\lambda^{\alpha} \lambda_{\alpha i}\right) n=a v_{i}-\mu \lambda_{i}
$$

where

$$
\begin{aligned}
& v_{i}=\frac{1}{4 s}\left(s \lambda_{\alpha i,}^{\alpha}-\rho \lambda^{\alpha} \lambda_{\alpha i}\right) ; a=a_{\alpha \beta} g^{\alpha \beta} ; \mu=\lambda_{\alpha \beta} g^{\alpha \beta}, \\
& \frac{1}{n}\left(a v_{i}-\mu \lambda_{i}\right) g_{j k}+\frac{1}{n}\left(a v_{j}-\mu \lambda_{j}\right) g_{i k}-v_{i} a_{j k}-v_{j} a_{i k}+\lambda_{i} \lambda_{k j}-\lambda_{k i} \lambda_{j}=0 .
\end{aligned}
$$

Then, let us alternate it by indices $j, k$

$$
\frac{1}{n}\left(a v_{j}-\mu \lambda_{j}\right) g_{i k}+\frac{1}{n}\left(a v_{k}-\mu \lambda_{k}\right) g_{i j}-v_{j} a_{i k}-v_{k} a_{i j}+\lambda_{k i} \lambda_{j}-\lambda_{j i} \lambda_{k}=0 .
$$

In the latter equation, let us re-assign indices $\mathrm{i}$ and $\mathrm{k}$ and the obtained expression can be added to (41). After these transformations we obtain

$$
\frac{1}{n}\left(a v_{j}-\mu \lambda_{j}\right) g_{i k}-v_{j} a_{i k}+\lambda_{j} \lambda_{k i}=0 \text {. }
$$

Let us wrapp (43) with $\xi^{j}$, then we get

$$
\lambda_{i, j}=A g_{i j}+B a_{i j}
$$

here

$$
B=\frac{1}{n} v_{\alpha} \xi^{\alpha} ; A=\frac{1}{n}\left(\mu \lambda_{\alpha}-a v_{\alpha}\right) \xi^{\alpha} .
$$

It is clear that

$$
A=\frac{1}{n}(\mu-a B) \text {. }
$$

Thus, the following is true

Theorem 2. When a pseudo-Riemannian space that permits $\varphi($ Ric $)$-fields, permits nontrivial geodesic mappings too, the a system of equations (5), (44) has a solution with a necessity. 


\section{DISCUSSION OF THE RESULTS OF THE STUDY}

Thus, we obtained an equation (44) that characterizes pseudo-Riemannian spaces permitting non-trivial geodesic mappings and permitting $\varphi($ Ric $)$-fields. These spaces are well-known in the theory of geodesic mappings and were studied earlier in relation to the studies on geodesic mappings of Einstein spaces. However, a direct transfer of the obtained results is hampered by peculiarities of Einstein spaces and requires an additional research.

\section{CONCLUSIONS}

The paper simplified a linear form of basic equations of theory of geodesic mappings for pseudo-Riemannian spaces that permit $\varphi($ Ric $)$-vector fields.

The obtained results are applicable to study on conformal mappings of Einstein spaces both locally and globally $[5,6]$ as well as to a study on quasi-Einstein spaces $[4,7]$.

Profound correspondences exist between theory of geodesic mappings of pseudoRiemannian spaces and theory of holomorpical projective mappings of Kahlerian spaces. Important perspectives are opened by application of methods of topology.

An actual problem is constituted by construction of examples and classification of the above-mentioned spaces.

\section{References}

1. Aminova, V. (1993). Pseudo-Riemannian manifolds with common geodesies. Russian Math. Surveys, 48(2), 105-160.

2. Hinterleitner, I., Kiosak, V. (2009). $\varphi($ Ric)-Vector Fields on Conformally Flat Spaces. Proceedings of American Institute of Physics, 1191, 98-103; doi.org/10.1063/1.3275604.

3. Hinterleitner, I., Kiosak, V. (2008). $\varphi$ (Ric)-Vector Fields in Riemannian Spaces. Archivum Mathematicum, 44(3), 385-390.

4. Kiosak, V., Lesechko, O., Savchenko, O. (2018). Mappings of Spaces with Affine Connection. 17th Conference on Applied Mathematics, APLIMAT 2018, Proceedings, Bratislava, 563-569.

5. Kiosak, V. A., Matveev, V. S. (2009). Complete Einstein metrics are geodesically rigid. Comm. Math. Phys., 289(1), 383-400.

6. Kiosak, V., Matveev, V. (2014). There exist no 4-dimensional geodesically equivalent metrics with the same stress-energy tensor. Journal of Geometry and Physics, 78, 1-11.

7. Kiosak, V. A., Matveev, V. S., Mikes, J., Shandra, I. G. (2010). On the degree of geodesic mobility for Riemannian metrics. Mathematical Notes, 87(4), 586-587.

8. Levi-Civita, T. (1896). Sulle transformationi delle equazioni dinamiche. Ann. Mat. Milano, Ser. 2., $24,255-300$.

9. Sinyukov, N. S. (1979). Geodesic mappings of Riemannian spaces. M.: Nauka, 255. (in Russian).

10.Thomas, T. Y. (1925). On projective and equiprojective geometries of paths. PWC. Nat. Acad. Sci. USA, 11, 198-203.

11.Weyl, H. (1921). Zur Innitesimalgeometrie Einordnung der projectiven und der konformen Auassung. Gottinger Nachtr, 99-112.

\section{Література}

1. Aminova V. Pseudo-Riemannian manifolds with common geodesies /V. Aminova // Russian Math. Surveys. $-1993 .-48(2)$. - P. 105-160.

2. Hinterleitner I. $\varphi$ (Ric) -Vector Fields on Conformally Flat Spaces / I. Hinterleitner, V. Kiosak // Proceedings of American Institute of Physics. - 2009. - 1191. - P. 98-103; doi.org/10.1063/1.3275604.

3. Hinterleitner I. $\varphi($ Ric) -Vector Fields in Riemannian Spaces / I. Hinterleitner, V. A. Kiosak// Archivum Mathematicum. - 2008. - 44(3). - P. 85-390. 
4. Kiosak V. Mappings of Spaces with Affine Connection / V. Kiosak, O. Lesechko, O. Savchenko // 17th Conference on Applied Mathematics. APLIMAT 2018. - Procedings, Bratislava. - 2018. - P. 563-569.

5. Kiosak V. A. Complete Einstein metrics are geodesically rigid / V. A. Kiosak, V. S. Matveev // Comm. Math. Phys. - 2009. - 289(1). - P. 383-400.

6. Kiosak V. There exist no 4-dimensional geodesically equivalent metrics with the same stressenergy tensor / V. Kiosak, V. Matveev // Journal of Geometry and Physics. - 2014. - 78. - P. 1-11.

7. Kiosak V. A. On the degree of geodesic mobility for Riemannian metrics /V. A. Kiosak, V. S. Matveev, J. Mikes, I. G. Shandra // Mathematical Notes. - 2010. - 87(4). - P. 586-587.

8. Levi-Civita T. Sulle transformationi delle equazioni dinamiche/T. Levi-Civita// Ann. Mat. Milano, Ser. 2. - 1896. - 24. - P. 255-300.

9. Синюков Н. С. Геодезические отображения Римановых пространств / Н. С. Синюков //. - М.: Наука, 1979. - 255c.

10. Thomas T. Y. On projective and equiprojective geometries of paths / T. Y. Thomas // PWC. Nat. Acad. Sci. USA. - 1925. - 11. - P. 198-203.

11.Weyl H. Zur Innitesimalgeometrie Einordnung der projectiven und der konformen Auassung / H. Weyl // Gottinger Nachtr. - 1921. - P. 99-112.

\section{Kiosak Volodymyr}

Odessa State Academy of Civil Engineering and Architecture,

Doctor of Physical and Mathematical Sciences, professor

Didrihsona str.,4 Odessa, Ukraine 65029

kiosakv@ukr.net,

ORCID: 0000-0002-7433-6709

Lesechko Oleksandr

Odessa State Academy of Civil Engineering and Architecture, Ph.D., associate professor

Didrihsona str.,4 Odessa, Ukraine 65029

a.lesechko@ukr.net,

ORCID:0000-0002-2352-6174

For references:

Kiosak, V., Lesechko, O. (2020). Geodesic mapping of spaces with special vector fields, Mechanics and

Mathematical Methods, 2 (1). 45-54.

Для посилань:

Кіосак В. А. Геодезичні відображення просторів зі спеціальними векторними полями / В. А. Кіосак, О. В. Лесечко // Механіка та математичні методи. - 2020. - Том 2, Вип. 1. - С. 45-54. 